\title{
Gambaran Pendekatan Model Copa pada Perawat Pelaksana di Rumah Sakit Abdul Manap Kota Jambi
}

\author{
Dwi Yunita Rahmadhani \\ Program Studi S2 Keperawatan, Kekhususan kepemimpinan dan manajemen keperawatan \\ Universitas Andalas Padang \\ Correspondence email: dwi.azkaya@gmail.com
}

\begin{abstract}
The safety of hospital patients is the hospital system to make patient care safer. Safe from the possibility of the risk of Patient Safety Incidents (IKP). One that can override the Model COPA patient safety is requesting more competent, safe practices, verified by examination performance. This study used a descriptive correlation design with cross sectional approach. The goal is to obtain COPA analysis model approach and the determinant factors of nurses with patient safety. The population is all nurses in inpatient hospital Abdul Manap city of Jambi. The number of samples in this study were 50 nurses using total sampling technique. In the bivariate analysis, obtained variables skills assessment and intervention, communication, critical thinking, human caring and relations of social, management, leadership, teaching and integration of science, gender, type of education, length of work, married status, employment status, accreditation campus, GPA, there is a significant association with patient safety with p-value <0.005. Meanwhile, to test each dependent variable and independent variables used chi square test. Multivariate analysis using logistic regression. For that to hospitals in hiring the necessary consideration in terms of the skill factor, for workforce training nurses for patient safety and hospital complements the SPO and equipment less.
\end{abstract}

Keyword: model COPA, patient safety, safe practices

\section{PENDAHULUAN}

Rumah sakit perlu mengembangkan diri dengan menyelenggarakan pelayanan yang berkualitas dan memberi kepuasan terhadap konsumen. Pelayanan dapat dikatakan berkualitas dan bermutu apabila rumah sakit mampu memberikan pelayanan lebih baik dari yang diharapkan oleh konsumen. Pelayanan yang berkualitas dan bermutu dapat tercipta dengan memberikan pelayanan prima. Pelayanan prima dapat tercipta apabila seluruh SDM rumah sakit memiliki keterampilan khusus diantaranya memahami produk secara mendalam, berpenampilan menarik, bersikap ramah dan bersahabat, peka (responsive) terhadap pasien, mengusai pekerjaan, mampu menanggapi keluhan pasien secara professional serta efektif (Anjaryani, 2009). Penelitian yang dilakukan oleh Otani, K., et al (2009) menyatakan bahwa pelayanan keperawatan menjadi salah satu indikator terciptanya pelayanan yang berkualitas dan bermutu setelah pelayanan staff rumah sakit.

Menurut Lumenta (2008), proses penjaminan mutu yang dilakukan rumah sakit telah berfokus pada 3 elemen yang ada dalam suatu organisasi rumah sakit, yaitu struktur, proses pelayanan, dan outcome. Sejak tahun 1990 rumah sakit telah melakukan berbagai hal untuk meningkatkan mutu pada 3 elemen penjamin mutu tersebut melalui pengembangan standar pelayanan rumah sakit, Quality Assurance, Total Quality Management, Akreditasi, Audit Medis/Clinical indicator dan lain sebagainya, kenyataan yang ada menunjukkan bahwa di rumah sakit selalu ada kejadian yang tidak diinginkan (KTD).

Namun harus diakui kegiatan institusi rumah sakit dapat berjalan apabila ada pasien. Karena itu keselamatan pasien merupakan prioritas utama untuk dilaksanakan dan hal tersebut terkait dengan isu mutu dan citra perumahsakitan (Putra, 2012).

Tuntutan pelayanan yang berkualitas tidak semata berdasarkan keselamatan pasien saja namun perlu menawarkan hasil maksimal berupa pelayanan yang berdasarkan SDM yang terstandarisasi yang memiliki kompetensi pengetahuan, keterampilan, konsep diri, motif dan ciri/sifat bawaan. Kompetensi pengetahuan dan keterampilan merupakan modal dasar untuk mencapai kompetensi lainnya (Haffizurachman, 2009). Trisnantoro (2005) dalam anggraini (2011) menyatakan bahwa saat ini semua rumah sakit pemerintah dan swasta kekurangan tenaga perawat selain jumlahnya kurang mutunya pun sering dikeluhkan. Keadaan seperti ini yang mewajibkan perawat harus memiliki kompetensi yang baik dalam memberikan pelayanan keperawatan kepada pasien. Kompetensi perawat tidak hanya berfokus pada kemampuan kognitif (pengetahuan), dan keterampilan (hard competency), namun harus didukung dengan perilaku/sikap mau memberikan pertolongan kepada orang lain khususnya pada pasien.

Standar kompetensi perawat merefleksikan atas kompetensi yang diharapkan dimiliki oleh individu yang akan bekerja di bidang pelayanan keperawatan. Menghadapi era globalisasi, standar tersebut harus ekuivalen dengan standar - standar yang berlaku pada sektor industri kesehatan di Negara lain serta dapat berlaku secara internasional. Ranah dan unit kompetensi perawat menurut PPNI (2005) meliputi 1).Praktik professional, etis, legal dan peka budaya dengan cakupannya mampu bertanggung gugat terhadap praktik professional, 2). Pemberian asuhan keperawatan dan 
manajemen asuhan keperawatan, serta 3). Pengembangan professional. Berdasarkan uraian menurut PPNI tersebut, kompetensi perawat juga dapat mengacu kepada model COPA (Competency Outcome Performance Assessment) yang pertama kali dicetuskan oleh Lenburg pada tahun 1990 (Wdyarini, 2005).

Menurut Lenburg (1999) yang dikutip dari penelitian (Widyarini, 2005) Model COPA berupa kerangka susunan kompetensi dan pengukuran kinerja yang dapat diterapkan untuk berbagai jenis pekerjaan jasa pelayanan, termasuk untuk perawat. Dalam Model COPA, semua keterampilan dan kemampuan perawat dapat dikelompokkan satu atau lebih dari delapan inti kompetensi. Model COPA adalah model yang komprehensif, kerangka konsep terstruktur, adanya kompetensi inti, dan metode yang dirancang untuk mempromosikan focus pada kompetensi dan praktek pendidikan keperawatan. Model ini diselenggarakan oleh empat konsep penting, karena pilar-pilar pendukung yang tertanam dalam empat pertanyaanyang mendukung perubahan keputusan.

Berdasarkan penelitian yang dilakukan oleh Widyarini (2005) mengenai kompetensi professional perawat, maka seperti yang diharapkan dan dapat disusun suatu teori mengenai profesionalisme perawat dari perspektif pasien. Berbagai jenis keterampilan seperti yang dituangkan oleh konsep Model COPA juga ditemukan dalam kenyataan dilapangan seperti keterampilan komunikasi meliputi oral, menulis, keterampilan kepemimpinan kepala ruangan serta berfikir kritis dalam menyelesaikan tindakan seperti menyelesaikan konflik antar sesama, mengambil tindakan yang sifatnya dapat membahayakan pasien. Fenomena selama ini di lapangan masih disebut bahwa perawat itu judes, kasar dan suka mengatur sendiri.

Berdasarkan hasil observasi yang peneliti lakukan dapat ditemui dari 8 perawat yang melakukan perlindungan, keamanan diri, assessment serta monitoring pada diri sendiri dan pasien hanya 2 orang seperti penggunaan handscoon, masker, penggunaan kateter lebih dari 1 minggu pada pasien yang berisiko infeksi serta alat pelindung diri pada pasien secara umum. Komunikasi yang dilakukan oleh perawat hanya berupa hal-hal yang dianggap perlu saja seperti penggantian alat invasive, sementara kebutuhan dasar pasien semua diserahkan pada keluarganya saja. Perawat di rumah sakit ini sebagian besar sudah dapat berfikir kritis seperti kepala ruangan mampu mengambil keputusan yang prioritas seperti pembagian jadwal dinas dengan tingkat ketergantungan pasien yang ada diruangan. Selanjutnya untuk promosi kesehatan jarang sekali dilakukan. Disamping itu juga dijelaskan bahwa tenaga keperawatan yang ada di Rumah Sakit Abdul Manaf belum mengaplikasikan budaya safety seperti cuci tangan 6 langkah dan perawat sering lupa terhadap moment cuci tangan. Insiden pasien jatuh cukup bermakna sekali karena pada dua tahun berturut-turut dari tahun 2012-2013 terdapat kejadian pasien jatuh di ruang anak sebanyak dua anak, yang seharusnya pasien jatuh itu tidak terdapat sama sekali dalam satu tahun serta pagar tempat tidur jarang digunakan dan dikontrol, handscoon yang digunakan untuk perawatan luka tidak steril karena masih menggunakan handscoon sekali pakai/disposible.

Mengacu pada permasalahan diatas perlu dilakukan "analisis Kompetensi Model COPA dan Faktor Determinan pada Perawat Pelaksana dengan Keselamatan Pasien Di Rumah Sakit Abdul Manap Kota Jambi". Hasil penelitian tersebut diharapkan dapat memberikan masukan bagi rumah sakit mengenai bagaimana kualitas layanan perawat dan upaya peningkatan mutu layanan yang akan memuaskan pelanggannya.

\section{METODE}

Penelitian ini merupakan jenis penelitian Deskriptif kuantitatif dengan pendekatan cross sectional study, yaitu setiap variable diamati pada saat bersamaan pada waktu penelitian berlangsung. Pendekatan ini dilakukan bertujuan untuk melihat bagaimana gambaran pendekatan Model COPA (keterampilan assessment dan intervensi, keterampilan berkomunikasi, keterampilan berfikir kritis, keterampilan human caring dan relasi social, keterampialn manajemen, keterampilan kepemimpinan, keterampilan pengajaran, keterampilan mengintegrasikan ilmu pengetahuan) dan

\section{HASIL DAN PEMBAHASAN Pendekatan Model COPA}

Tabel 1. Distribusi Frekuensi Responden Menurut COPA Model Di Rumah Sakit Abdul Manap Kota Jambi Tahun 2015

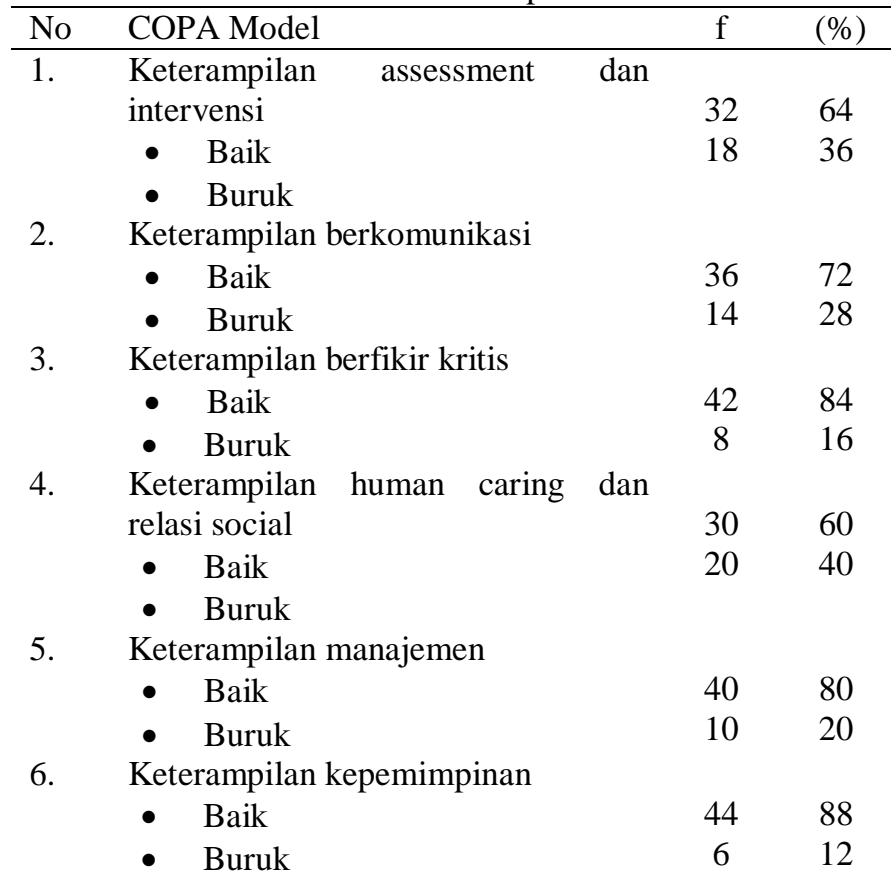


7. Keterampilan pengajaran

- $\quad$ Baik

- Buruk

$27 \quad 54$

$23 \quad 46$

8. Keterampilan mengintegrasikan pengetahuan

$31 \quad 62$

- Baik

$19 \quad 38$

- Buruk

9. Composit Model Copa
- Baik
24

- Buruk

$26 \quad 52$

Tabel 1 menunjukan bahwa dari 50 perawat, lebih dari setengah (64\%) memiliki keterampilan assessment dan intervensi yang baik, (72\%)dengan keterampilan komunikasi yang baik. Sebagian besar (84\%) perawat mempunyai keterampilan berfikir kritis yang baik. Lebih dari setengah perawat $(60 \%)$ mempunyai keterampilan human caring dan relasi sosial baik, dan sebagian besar $(80 \%)$ perawat mempnyai keterampilan manajemen baik.Sebaliknya sebagian besar $(88 \%)$ perawat juga mempunyai keterampilan kepemimpinan yang buruk.Setengahnya (54\%)perawat mempunyai keterampilan pengajaran yang baik. Dan lebih dari setengah $(62 \%)$ mengintegrasikanilmu pengetahuan. Jadi, untuk total pendekatan model Copa yang di miliki oleh perawat pelaksana adalah lebih dari setengah (52\%) perawat mempunyai kompetensi model COPA yang buruk.

\section{Keselamatan Pasien}

Tabel 2. Distribusi Frekuensi Responden Berdasarkan Penilaian Tindakan dalam Keselamatan PasienDi Rumah Sakit Abdul Manap Kota Jambi Tahun 2015

\begin{tabular}{lcc}
\hline Keselamatan Pasien & $\mathbf{f}$ & $\mathbf{( \% )}$ \\
\hline Safety & $\mathbf{2 5}$ & $\mathbf{5 0}$ \\
Tidak Safety & $\mathbf{2 5}$ & $\mathbf{5 0}$ \\
Total Responden & $\mathbf{5 0}$ & $\mathbf{1 0 0}$ \\
\hline
\end{tabular}

Berdasarkan tabel 2 menunjukkan bahwa separuh (50\%) perawat pelaksana di Ruang Rawat Inap RS Abdul Manap dapat melakukan keselamatan pasien dengan safety.

\section{SIMPULAN}

Penelitian ini dapat disimpulkan sebagai berikut:

1. Pada umumnya pendekatan COPA Model pada perawat pelaksana baik di RS Abdul Manap Kota Jambi.

2. Setengah dari perawat melakukan keselamatan pasien dengan baik di Rumah Sakit Abdul Manap.

\section{Saran}

1. Bagi perawat pelaksana di Rumah Sakit abdul Manap Kota Jambi supaya mengexplore dan memperbaiki keterampilan yang dimiliki oleh diri untuk melakukan keselamatan pasien dengan sangat safety sehingga tidak akan terjadi insiden keselamatan pasien

2. Bagi pelayanan keperawatan supaya melakukan pelatihan keselamatan pasien dan pelatihan lainnya guna menambah pengetahuan perawat agar tidak muncul insiden keselamatan pasien di Rumah Sakit Abdul Manap Kota Jambi.

3. Bagi pihak manajemen Rumah Sakit Abdul Manap Kota Jambi untuk audit manajemen tentang kelengkapan SPO Keselamatan Pasien dan peralatan dilapangan guna mengurangi resiko terjadinya insiden keselamatan pasien

4. Bagi peneliti lanjut

Agar dapat melakukan penelitian lebih lanjut tentang pengaruh pelatihan keselamatan pasien terhadap asuhan keselamatan pasien.

\section{DAFTAR PUSTAKA}

Aboshaiqah, A.E. (2010). Safety culture: A Basaline assessment of nurses' perceptions in a Saudi Arabia Hospital. Proquest Disertation Publishing. Diunduh melalui http://search.proquest.com/doc. pada November 2014

AHQR. (2003). Publication No. 07-E005. Rockville, MD: Agency for Healtcare Research and Quality Maret: 151. www.ahrq.gov, diperoleh 9 Juli 2014

Arikunto, S. (2006). Manajemen Penelitian. Jakarta: Rineka Cipta

BAN-PT. (2007). Naskah Akademik Akreditasi Instituusi Perguruan Tinggi.

Being Open. Communicating Patient Safety Incident with Patiient and their Carers. The National Patient Safety Agency, (2005). http://www.npsa.nhs.uk/site/media/dokument/145 6_Beingopenpolicy1_11.pdf diperoleh 9 juli 2014

Boothman, R.C., Imhoff, S.A., \& Campbell, D.A. (2012). Nurturing a culture of patient safety \& achieving lower malpractice risk through disclosure: Lessons learned \& future directions. Frontiers of Health service management Vol.28/No.3. Diunduh melalui http://web.ebscohost.com/ehost/detail pada 15 September 2014

Boyer, S. (2002). Vermont Nurse intership Project: A collaborative enterprice developed by nurse leaders from education, practice, and regulation. Nursing Education Perspective.

(2008). Competence and innovation in preceptor development: updating our programs . Journal

Boediono. (2002). Pengembangan silabus kurikulum berbasis kompetensi. Jakarta: Pusat kurikulum Balitbang Depdiknas.

Cahyono, J.B.S.B. (2008). Membangun budaya keselamatan pasien dalam praktik

kedokteran. Yogyakarta: Penerbit Kanisius 
Canadian Nurses Association. (2009). Position statement patient safety. Ottawa:

The Author. Januari 14, 2010. http://www.cnaaiic.ca/cna/documents/pdf/ publications/PS102_Patient_Safety_e.pdf

Choo, J. Hutchinson, A., \& Bucknall, T. (2010). Nurses' role in medication safety. Journal of Nursing Management. Vol.18/No.5. Diunduh melalui http://web.ebscohost.com/ehost/detail?vid=8\&h pada 5 oktober 2015

Considine, J. (2005, Maret). The role of nurses in preventing adverse events related to respiratory dysfunction: Literature review. Journal of Advanced Nursing, 49 (6), 624-633.

Depkes. (2008). Panduan Nasional Keselamatan PasienRumah Sakit. Jakarta, KKPRS

--------. (2009). Undang-Undang Republik Indonesia No 44 Tahun 2009, tentang Rumah Sakit, Jakarta

--------. (2009). Undang-Undang Republik Indonesia No 36 Tahun 2009, tentang Kesehatan, Jakarta - (2011). Peraturan Menteri Kesehatan Republik Indonesia. No 1691/Menkes/Per/VIII/2011. Tentang Keselamatan Pasien Rumah Sakit

Dhatt, G.S., Damir, H.A., S., Krishnan, S., \& James, D.M. (2011). Patient safety: patient identification wristband errors. Clinical Chem Laboratory Medicine. Vol.49/No.5 diunduh melalui http://web.ebscohost.com/ehost/detail?vid=14\&hi $\mathrm{d}=127$ pada 5 september 2013

Dineen. (2002). Six steo to root cause analysis consequence. Oxford. ISBN

Flynn, L., Liang, Y., Dickson, G.L., Xie, M., \& Suh, D.C. (2012). Nurses' practice environments, error interception practices, and inpatient medication errors. Journal of Nursing Scolarship. Diunduh melalui

http://web.ebscohost.com/ehost/detail?vid=12\& pada 5 September 2015

Gillies, D.A. (1994). Nursing management: a sistem approach. (3 ed.)Phyladelphia: WB. Saunders Company

Henriksen, K., et Al (2008). Patient Safety and Quality: an evidence base handbook for nurse. Rockville MD: Agency for Healthcare Research and Quality Publications. February 2011, http://www.ahrq.gov.gov/QUAL/nurseshdbk/ Diperoleh 8 Juli 2014

Hughes, R.G (2008). Patient safety and quality: an evidence-based handbook for

nurses. Rockville MD: Agency for Healthcare Research and Quality

Publications. Januari 2010. http://www.ahrq.gov/QUAL/nurseshdbk/

International Council of Nurse (2002). Position statement patient safety. Geneva:

The Author. Januari 14, 2010. http://www.icn.ch.
Joint Commision International, Standar Akreditasi Rumah Sakit, Enam Sasaran Keselamatan Pasien. Edisi ke -4 Januari 2011

Kementerian Kesehatan RI. (2008). Kemenkes 129 tentang Standar Pelayanan minimal rumah sakit. Diunduh melalui http://idscribd.com/doc.38737711/kepmenkes129-thn-2008-Spm-Rs pada 8 September 2014

Komisi Disiplin Ilmu Kesehatan. (2002). Praktek keperawatan ilmiah. Jakarta:

The Author.

Komite Keselamatan Pasien Rumah Sakit (KKPRS). (2008). Pedoman pelapoan insiden keselamatan pasien (IKP). Jakarta: KKPRS

Lenburg, C.B. (1979). The Clinical Performance Examination: Development and Implementation. New York: Appleton-Century-Crofts. - (1999). The framework, concepts and methods of the Competency Outcomes and Performance Assessment (COPA) Model. Online Journal of issues in Nursing. Retrieved from www.nursingworld.org/MainMenuCategories/AN AMarketplace/ANAPeriodicals/OJIN/TableofCon tents/Volume41999/No3Sep1999/COPAModel.as px.

(2005). The competency outcome and performance assessment model applied to nursing case management systems. In E.Cohen \& T.Cesta (Eds), Nursing case management: from essentials toadvanced practice applications $\left(4^{\text {th }}\right.$ ed., pp263276). St Louis, MO: Elsevier Mosby.

-------. (2010). Competency outcomes and performance assessment for contemporary nursing education. In L. Caputi (Ed), Teaching nursing: The art and science.

--., Klein, C., Abdur-Rahman, V., Spencer, T., \& Boyer, S. (2009). The COPA Model: A comprehensive framework designed to promote quality care and competence for patient safety. Nursing educationPerspectives, 30, 312-317

Lumenta, N.A (2008). State of the art patient safety. Disampaikan pada Workshop

Keselamatan Pasien dan Manajemen Resiko Klinis di RSAB Harapan Kita

pada tanggal 1-3 April 2008. Jakarta: Tidak Dipublikasikan.

Maxson, P., Derby, K.M., Wrobleski, D.M., \& Foss, D.M. Bedside nurse-to-nurse handoff promote patient safety. Medical Surgical.Vol.21/No.3. Diunduh melalui http://web.ebscohost.com/ehost/detail?vid=27\&hi $\mathrm{d}=118 \&$ sid=b9117e5d-bab1-4cae-9010-559fl40 pada 8 september 2015

Mulyasa (2005). Kurikulum Berbasis Kompetensi: Konsep, karakteristik dan implementasi. Bandung: Penerbit PT Remaja Rosdakarya. 
Murphy, M.F. \& Kay, J.D.S (2004). Patient identification: problems and potential solutions. Blackwell Publishing Ltd.vox Sanguinis. Vol.87/No.2. diunduh melalui http://ebscohost.com/ehost/detail?vid=30\&sid=b9 117e5d-bab1-4 pada 9 September 2012

Notoatmodjo, S. (2010). Metodologi penelitian. Jakarta: PT Rineka Cipta

Persatuan Perawat Nasional Indonesia. (2010). Standar profesi dan kode etik

perawat indonesia. Jakarta: The Author.

Potter , P.A., \& Perry, A.G. (2009). Fundamental of Nursing. 7 Edision. Singapore: Elsevier Inc.

Putra, H (2013). Panduan pemahaman dan pengelolaan pasien resiko jatuh di RSUP DR. M. DJAMIL Padang. Padang

Reiling, R.T (2006, August). Creating a culture of patient safety through innovative hospital design. Journal Advance in Patient Safety. 2 (20), 1-15. http://www.ahrg.gov.

Robbins, S.P (2001). Organizational behavior: Concept, controversies, and applications. ( ${ }^{\text {th }}$ ed). New Jersey: Prentice Hall International.

Siagian, S.P. (2006). Manajemen sumber daya manusia. Jakarta: PT Rineka Cipta

Stanton, M.W. (2004). Hospital nurse staffing and quality of care. Januari 24 ,

2010.

http://www.ahrq.gov/research/nursestaffing/nurses taff.pdf

Storr, J., Topley, K., \& Privett, S., (2005). The ward nurse's role in infection control. Nursing Standard. 19, 41, 56-64. Diunduh melalui http://web.ebscohost.com/ehost/detail?vid=15\&hi $\mathrm{d}=105 \&$ sid $=834 \mathrm{bc} 725-6 \mathrm{a} 08-4 \mathrm{ccf}-\mathrm{b} 2 \mathrm{~b} 5-$

f6e0e6722704\%40sessionmgr114\&bdata $=\mathrm{JnpdG}$ pada 8 September 2015

Sugiyono. (2008). Metode penelitian kuantitatif, kualitatif dan RB. Bandung: CV

Alfabeta.

Suryabrata, S. (2005). Metodologi penelitian. Jakarta: PT Raja Grafindo Persada.

WHO. (2004). World Alliance for Patient Safety, Format Program. Januari 03,

2010. http://www.who.int . (2007). Nine Life Saving Patient Safety Solution. Januari 03, 2010.

http://www.who.int

-----. (2009). Human Factors in Patient safetyreview of topic and tool : Report for methods and measures working groupof WHO patient safety. WHO/IER/PSP/2009.05. Diunduh melalui www.who.int.patientsafety pada 5 september 2014

Widyarini, Nilam. (2005). Makna profesionalisme perawat dalam persfektif pasien. Jurnal Fakultas Psikologi Universitas Gunadarma.
Yahya (2006). Konsep dan program patient safety. Disampaikan dalam konvensi Nasional Mutu Rumah Sakit VI, Bandung

Yulia, H. (2011). Analisis Determinan Kejadian Nyaris Cedera dan Kejadian Tidak Diharapkan di Unit Perawatan Rumah Sakit Pondok Indah Jakarta. Tesis FIK UI. Tidak dipublikasikan. 